\title{
Influence of dizziness on quality of life of school children: application of the dizzeness handicap invertory child and adolescent-dhi-ca
}

\begin{abstract}
Introduction: Bodily balance is maintained by integration of the receptors localized in the vestibular, visual and somatosensory systems that are integrated into the central nervous system. Physiological changes due to chronic diseases, musculoskeletal disorders and neurological lesions, among others, may affect the systems responsible for controlling postural balance.
\end{abstract}

Objective: To identify the domain most affected in schoolchildren by means of using the Dizziness Handicap Inventory Child/Adolescent (DHI-CA).

Material and method: A retrospective study of a quantitative nature was conducted in 15 municipal school units of the Cabula-Beiru District and at the Phonoaudiology Clinic of the State University of Bahia, localized in the city of Salvador/Bahia/Brazil. The study was approved by the Research Ethics Committee of the State University of Bahia (Brazil) by means of Report No. 179,799/13. The instrument Dizziness Handicap Inventory Child/Adolescent (DHI-CA) 7 was used for data collection. The purpose of this questionnaire was to evaluate the impact of dizziness on the quality of life of children and adolescents with dizziness, to enable quantification of the effects imposed on the functions of daily life, and to help with the choice of treatment. Retest was performed with an interval of seven to ten days after the first application, with the purpose of preventing changes in the schoolchildren's general state of health.

Results: Of the 119 children and adolescents selected for the study, only 33 showed up in the two time intervals of application of the DHI-CA. In the first application, the functional domain was the most affected, showing the highest score in $66.6 \%$ of the 33 schoolchildren. In the second time interval, the DHI-CA was applied gain, and 66,6 $\%$ of the schoolchildren showed the functional domain to be the most affected.

Conclusion: From this study, the functional domain was perceived to remain the most changed in the two time intervals of application of the DHI-CA, therefore, there was consistency of the responses. This study demonstrated that there was a greater impact on the quality of life of the studied population, related to the functional aspect of the instrument used - the DHI-CA.
Volume I Issue 5 - 2017

\author{
Maria da Glória Canto de Sousa, Gabriela \\ Carvalho Machado \\ Professor of Speech Therapy, State University of Bahia, Brazil
}

Correspondence: Maria da Glória Canto de Sousa, Professor of Speech Therapy, State University of Bahia, Brazil, Email eduardopondedesena@gmail.com

Received: July 20, 2017 | Published: September II, 2017

\section{Introduction}

Perception of the environment is constantly monitored by the sensory receptors of position and movement. Bodily balance is maintained by integration of the receptors localized in the vestibular, visual and somatosensory systems that are integrated into the central nervous system. ${ }^{1}$ Physiological changes due to chronic diseases, musculoskeletal disorders and neurological lesions, among others, may affect the systems responsible for controlling postural balance. ${ }^{2}$ Efferent stimuli coming from the visual, vestibular and proprioceptive systems coordinated by the brain and integrated into the central nervous system are responsible for maintaining balance of the body. Symptoms such as dizziness, nausea or vertigo when moving, in addition to tinnitus the ears and difficulty with hearing may be indications of vestibular disturbances. Invariably, children have difficulty with describing these sensations and system, many of these may not be identified by parents and teachers. ${ }^{3}$

Dizziness and vertigo frequently occur in childhood and adolescence, and are more common than we used to think. ${ }^{4}$ Vertigo is a mistaken sensation of movement and is a common sign of vestibular dysfunction. In children, it is important to determine whether the vertigo is secondary to problems such as cerebellar ataxia or dysfunction. ${ }^{5}$ Adequate and early differential diagnosis ${ }^{4}$ in children and adolescents with dizziness, vertigo and headaches, requires the use of methods that are not very invasive, and they must be clinically managed by means of an approach that includes not only specific treatment, but family educational strategies to obtain good results with the treatment. ${ }^{6}$ Oral and written language disturbances may be the consequence of compromised physical balance, motor coordination and bodily posture, which make spatial relations difficult, change children's learning ability and communication skills. ${ }^{1}$

The incapacity caused by dizziness, whether it be in the emotional, functional or physical domain, is of great importance in the social and personal context of the individual, regardless of its etiology, since it considerably affects their quality of life. ${ }^{7}$ There is generally a consensus in the field of health to ensure that children have a standard of living that allows them adequate physical, mental and social development. ${ }^{8}$ Often, because of the limitations imposed by dizziness in the most severe cases, many parents reduce their expectations about their children's participation in various daily 
activities, compromising, above all, their quality of life. ${ }^{9}$ Standardized functional rating scales are available in many different rating systems. The literature has several scales of self-assessment for people with vestibular disorders and balance, which can be given, including by the patients themselves. ${ }^{10}$ The most common questionnaires and scales include questions about dizziness or assessing balance disorders and are divided according to their use. ${ }^{11}$

Dizziness Handicap Inventory (DHI) was developed in response to a lack of tools to identify functional, emotional, and physical problems associated with impaired balance. Functional incapacity manifests itself as the impossibility of performing basic tasks associated with daily life in the professional, occupational and recreational field. The emotional includes the psychological and/or psychiatric consequences that arise as a result of organic problems, such as anxiety, depression or panic, that alter the development of day to day activities. In turn, physical disability is defined as a set of disadvantages experienced by the individual as a functional and / or organic result of the deterioration of one or more systems. ${ }^{7}$ In addition to measuring the impact of dizziness on individuals' quality of life, DHI also reports on the degree of dizziness disability that varies according to full scale and subscale scores. ${ }^{12}$ Therefore, it is important to point out the relationship between vestibular diseases and difficulties at school found in children which may harm their interaction with the social medium in which they live.

\section{Objective}

To identify the domain most affected in schoolchildren by means of using the Dizziness Handicap Inventory Child/Adolescent (DHICA).

\section{Materials and method}

A retrospective study of a quantitative nature was conducted in 15 municipal school units of the Cabula-Beiru District and at the Phonoaudiology Clinic of the State University of Bahia, localized in the city of Salvador/Bahia/Brazil. The study was approved by the Research Ethics Committee of the State University of Bahia (Brazil) by means of ReportNo.179,799/13.The instrument Dizziness Handicap Inventory Child/Adolescent (DHI-CA) ${ }^{13}$ was used for data collection. The purpose of this questionnaire was to evaluate the impact of dizziness on the quality of life of children and adolescents from 6 to 14 years with dizziness, to enable quantification of the effects imposed on the functions of daily life, and to help with the choice of treatment. Retest was performed with an interval of seven to ten days after the first application, with the purpose of preventing changes in the schoolchildren's general state of health.

The DHI-CA is composed of 25 questions, organized into three subscales: Functional (nine items); Emotional (nine items); and Physical (seven items). The responses are divided into "yes", "sometimes" and "no", with scores of 4 points for the response "yes"; 2 points for "sometimes", and no point for the response "no". The maximum score for the physical subscale is 28 points; for Emotional, 36 points; and for Functional, 36 points, totaling 100 points. ${ }^{14}$ Considering the total score, the degree of incapacity may be slight ( 0 to 30 points); moderate ( 30 to 60 points); or severe (over 60 points). ${ }^{15}$ Considering the emotional and functional subscales, the degree of incapacity may be nonexistent ( $0-14$ points), reveal moderate deficiency (15 to 24 points), or severe deficiency (over 25 points). Considering the physical subscale, the degree of incapacity may be nonexistent (0-9 points), reveal moderate deficiency (10 to 16 points), or severe deficiency (over 17 points). ${ }^{16}$ The functional domain of the DHI-CA evaluates the interference of dizziness in performing certain movements of the eyes, head and body, with focus on the capacity to perform social and leisure activities, and on the independence to perform tasks. The emotional domain, when the aspects investigated were compromised, they demonstrated possible harm to the quality of life, generating frustration, fear of leaving the house unaccompanied, or even staying at home alone, and shame about clinical manifestations. The concerns with changes in concentration, feeling of incapacity, changes in family or social relationship and depression also interfere in daily life activities. The physical aspects investigated by the DHI-CA were evaluated by means of the relationship between the appearance and aggravation of dizziness when body movements were made. ${ }^{11}$

\section{Results}

Of the 119 children and adolescents selected for the study, only 33 showed up in the two time intervals of application of the DHI-CA. In the first application, the functional domain was the most affected, showing the highest score in $66.6 \%$ of the 33 schoolchildren. In the second time interval, the DHI-CA was applied gain, and $66,6 \%$ of the schoolchildren showed the functional domain to be the most affected.

\section{Conclusion}

From this study, the functional domain was perceived to remain the most changed in the two time intervals of application of the DHICA.

\section{Acknowledgements}

None.

\section{Conflict of interest}

The author declares no conflict of interest.

\section{References}

1. Bittar RSM, Ganança FF. Decifrando a tontura. 2nd ed. São Paulo: Segmento Farma. 2010.

2. Albertino S, Albertino R. Reabilitação vestibular. Revista Hospital Universitário Pedro Ernesto, Brazil: Springer; 2012;11(3).

3. Meireles AE, Pereira LMDS, Oliveira TGD, et al. Alterações neurológicas fisiológicas ao envelhecimento afetam o sistema mantenedor do equilíbrio. Rev Neurociências. 2010;18(1):103-108.

4. Jahn K, Langhagen T Heinen F. Vertigo and dizziness in children. Current opinion in neurology. 2015;28(1):78-82.

5. Perez MLD, Lemos NFD, Aprile MR, et al. Queixas otoneurológicas em escolares. In: ENCONTRO INTERNACIONAL DE AUDIOLOGIA, Bauru. Anais eletrônicos. São Paulo, Brazil; 2015.

6. William QMD, Kedia SM. Dizziness and Orthostatic Intolerance in the Pediatric Headache Patient. Semin Pediatr Neurol. 2016;23(1):71-78.

7. Ayala LLM, Velásquez MIC. Evaluación de los pacientes con vértigo mediante el cuestionario de discapacidad por vértigo (DHI). Anales de Otorrinolaringología. 2014;59(1):59-65.

8. Prebianchi HB. Medidas de qualidade de vida para crianças: aspectos conceituais e metodológicos. Psicol teor Prá. 2003;5(1):57-69.

9. Li CM, Hoffman HJ, Ward BK, et al. Epidemiology of dizziness and balance problems in children in the United States: a population-based study. J Pediatr. 2016;171:240-247. 
10. Cohen HS. Assessment of functional outcomes in patients with vestibular disorders after rehabilitation. NeuroRehabilitation. 2011;29(2):173-178.

11. Rogula SS, Szmytke ZE. Przegląd skal i testów dla oceny czynnościowej pacjenta $\mathrm{z}$ zawrotami głowy i zaburzeniami równowagi. Otorynolaryngologia. 2015;14(3):141-149.

12. Jacobson GP, Newman CW. The development of the dizziness handicap inventory. Arch otolaryngol head neck surg. 1990;116(4):424-427.

13. Sousa MGC. Cruz O, Santos AN, et al. Brazilian adaptation of the dizziness handicap inventory for the pediatric population: reliability of the results. Audiol Commun Res. 2015;20(4):327-335.
14. Castro ASO, Gazzola JM, Natour J, et al. Versão brasileira do Dizziness Handicap Inventory. Pro Fono. 2007;19(1):97-104.

15. http://fisioterapiasinred.com/dizzinness-handicap-inventory/

16. Walteros D, Bernal E, Pineda AM, et al. Validez y confiabilidad del DHI versión colombiana. Corp Univ Iberoam. 2009;9(1):122-139. 